\title{
Persistence, Recurrence, and Progression Rates of Superficial Bladder Tumours after Resection Using the Differentiated Technique
}

\author{
S. Langbein ${ }^{a, d}$ \\ K. Badawi ${ }^{a} \quad$ A. Haecker ${ }^{a}$ \\ C. Weiss ${ }^{b}$ \\ M. Hatzinger ${ }^{a}$ \\ P. Alken ${ }^{a}$ \\ M. Siegsmund ${ }^{\mathrm{c}}$
}

Abteilungen für ${ }^{a}$ Urologie und ${ }^{b}$ Biostatistik, Universitätsklinikum Mannheim, Mannheim, und

${ }^{c}$ Krankenhaus am Urban, Akademisches Lehrkrankenhaus der Freien Universität Berlin, Berlin, Germany;

${ }^{d}$ Department of Urology, Academisch Medisch Centrum, University of Amsterdam, The Netherlands

\section{Key Words}

Bladder cancer - Differentiated resection technique • Recurrence/progression, superficial bladder cancer • Tumour persistence - Second tumour resection • Extracellular matrix

\begin{abstract}
Objective: To investigate whether the differentiated resection technique for excising superficial bladder cancer leads to higher recurrence and progression rates as compared with regular resection. Subjects and Methods: We evaluated 163 patients, 66 undergoing a differentiated and 97 a regular resection. All patients underwent a routine second resection within 6-10 weeks. Recurrence and progression rates as well as tumour persistence on second resection were analyzed. Results: Patients with differentiated resections of bladder tumours did not have higher tumour recurrence and progression rates. Also, these patients had a significantly higher percentage of tumour-free second resections ( $p=0.03$ ). Conclusion: The differentiated resection technique for excising superficial bladder cancer has no negative influence on recurrence and progression rates, but it leads to a reduced tumour persistence.
\end{abstract}

\section{Introduction}

The major problems in superficial bladder cancer are the high recurrence (50-70\%) and progression (10-50\%) rates. Transurethral resection is the first choice of treatment; unfortunately, the resection itself has never been standardized. The use of differing resection techniques, taking random biopsies, or performing second resections complicate the comparison of institutional results. Whether or not recurrent tumours originate from tumour cell implantation, field effect, or incomplete resection is debated. In routine second resections, residual tumour tissue has been found in 30-76\% of the cases [1]. A high percentage of synchronous and metachronous bladder tumours result from a single original tumour. This has been demonstrated by microsatellite analysis [2]. It has not been determined whether primary resection results in spreading of these tumours or whether the tumours have been seeded before treatment. It is difficult to ascertain whether resection itself has an impact on recurrence or progression.

Experimental data strongly indicate that cell implantation into the traumatized bladder wall plays an important role in tumour recurrence and progression. Uncoated extracellular matrix especially attracts tumour cells, providing ideal conditions for cell implantation in vitro [3].

\section{KARGER}

Fax +4161306 1234 E-Mail karger@karger.ch www.karger.com 
Table 1. Tumour stages and grades at first and routine second transurethral resection of the bladder (TURB) using the differentiated resection (DR) and the non-differentiated resection (non-DR) techniques; 100 second TURBs showed no evidence of tumour cells

\begin{tabular}{|c|c|c|c|c|}
\hline & \multicolumn{2}{|c|}{ First TURB (\%) } & \multicolumn{2}{|c|}{$\begin{array}{l}\text { Positive second } \\
\text { TURB }(\%)\end{array}$} \\
\hline & DR & non-DR & DR & non-DR \\
\hline \multicolumn{5}{|l|}{ Stage } \\
\hline $\mathrm{Ta}$ & $30(46)$ & $46(47)$ & $15(68)$ & $25(61)$ \\
\hline $\mathrm{T} 1$ & $36(54)$ & $50(52)$ & $4(18)$ & $9(22)$ \\
\hline CIS & 0 & $1(1)$ & $3(14)$ & $5(12)$ \\
\hline$>\mathrm{T} 1$ & 0 & 0 & 0 & $2(5)$ \\
\hline \multicolumn{5}{|l|}{ Grade } \\
\hline G1 & $12(18)$ & $22(22.5)$ & $7(32)$ & $15(36.5)$ \\
\hline G2 & 49 (74) & $53(55)$ & $10(45)$ & $15(36.5)$ \\
\hline G3 & $5(8)$ & $22(22.5)$ & $5(23)$ & $11(27)$ \\
\hline Total & 66 & 97 & 22 & 41 \\
\hline
\end{tabular}

Deep and extensive transurethral resections, as with the differentiated resection technique, may lead to increased recurrence and progression rates. Therefore, the aim of this study was to compare whether the differentiated resection technique for excising superficial bladder cancer leads to higher recurrence and progression rates than regular resections.

\section{Subjects and Methods}

Patients with primary and recurrent superficial bladder cancer treated with video-guided transurethral resection between 1993 and 2000 were included in this study. Inclusion criteria were routine second resections within 6-10 weeks and completely documented follow-ups. 163 patients, 134 male and 29 female, met the inclusion criteria: 66 patients were resected using the differentiated technique described by Bressel et al. [4], with separate deep resection of tumour base and tumour surroundings; 97 patients were resected using a non-differentiated technique with complete resection of all visible tumours. All first tumour resections were carried out by urologists in training, supervised by senior urologists, while the routine second resections were performed by senior urologists. Senior urologists determined the method of resection and treated their respective patients with their preferred technique.

Visible tumours, including detrusor muscle, were removed completely during transurethral resection; for histological staging, detrusor muscle had to be included. Routine second resection was performed within 6-10 weeks. Patients with unresectable and muscle-invasive tumours were excluded from this evaluation.

The minimum follow-up period was 48 months. The histological profile of the tumours determined the further treatment as recommended by the European Association of Urology (EAU) guide- lines. Mitomycin $\mathrm{C}$ was administered to 34 and 38 patients in the differentiated and in the non-differentiated resection groups, respectively, with an average of 11 and 14 instillations, respectively. Bacillus Calmette-Guérin therapy was administered in 3 and 6 patients with a mean of 5 and 8 applications in the differentiated and the non-differentiated resection groups, respectively. Repeat cystoscopy was done every 3 months for the first 24 months and every 6 months thereafter.

Tumour recurrence and progression rates in the differentiated resection group, with resection of visible tumours including surrounding tissues and an extra resection of the tumour base, were correlated with those in the non-differentiated resection group, where only visible tumour tissue was removed. Analysis of tumour persistence in routine second resection as well as overall recurrence and progression, influence of concomitant carcinoma in situ, early recurrences (24 months), and multifocality was carried out. Statistical analysis was performed using SAS software (version 8.2). Chisquare and Fisher's exact tests were used. The significance level was determined at alpha $=0.05$.

\section{Results}

The mean patient age was $67 \pm 9$ years. The clinical stage and grade distributions at first and second resection are given in table 1. Altogether, 244 transurethral resections for bladder tumours and 221 for second resections were performed. No significant difference was noted in between the groups concerning histological staging and grading $(p=0.8)$, low versus high grade $(p=0.5)$, or in application of intravesical chemotherapy $(p=0.6)$. All 163 patients showed transitional cell carcinoma. After 24 months, 14 of the 66 patients (21\%) in the differentiated resection group and 21 of the 97 patients $(22 \%)$ in the non-differentiated resection group had tumour recurrences $(\mathrm{p}=0.27)$. After 48 months, 18 of the $66(27 \%)$ patients and 28 of the 97 patients (29\%) had tumour recurrences in the differentiated and non-differentiated resection groups, respectively $(p=0.33)$. Progression from superficial to muscle-infiltrating tumours occurred in 2 (3\%) of the differentiated and in $5(5 \%)$ of the non-differentiated resection patients. Recurrence and progression rates did not show any significant difference between the two groups ( $\mathrm{p}=1.0$; fig. 1). Of the 163 patients, 59 $(36 \%)$ presented multiple tumours at first resection. One unifocal tumour (1\%) and 6 multifocal tumours (10\%) showed muscle-invasive growth patterns within 48 months. Statistically, there was a significant correlation between progression and a multifocal growth pattern $(p=0.005)$. In univariate analysis, concomitant carcinoma in situ was not a significant risk factor for progression. However, multifocality, carcinoma in situ, and early recurrence combined were statistically significant $(\mathrm{p}<$ 
Fig. 1. Kaplan-Meier plot with recurrence rates in patients treated with differentiated and non-differentiated resection techniques.

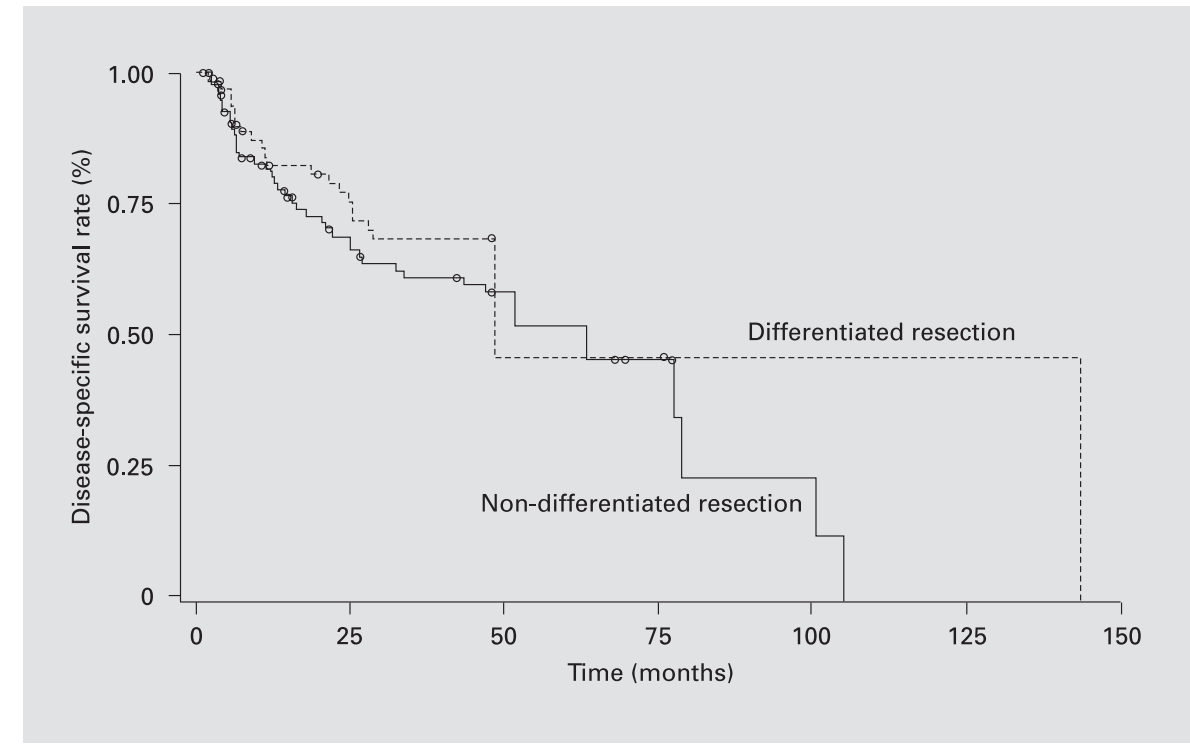

$0.05)$ parameters for the development of progression. In the differentiated resection group, 33\% of the patients had a positive second resection, as had $42 \%$ in the regular resection group $(\mathrm{p}=0.03)$.

\section{Discussion}

Differentiated resection was first described by Bressel et al. [4], suggesting lower tumour persistence with resection of tumour base and tumour surroundings. Studies on tumour persistence found that the proportion of residual tissue in routine second resections increased with tumour stage: 27 and 53\% in Ta and T1 tumours, respectively [5]. Flamm and Steiner [6], however, reported a lower tumour persistence rate of $10 \%$ in differentiated resected tumours, which is in accordance with our finding: $9 \%$ less tumour persistence in patients in whom the differentiated resection technique was applied. Considering that tumour tissue left behind will lead to new cancer growth, complete tumour elimination is of great importance. Still, the differentiated resection technique is not standard, because it may cause more severe urothelial defects and cancer cell implantation, leading to increasing recurrence and progression rates [7-10].

Whether or not deep transurethral resection enhances tumour progression is still under debate. El-Abbady et al. [11] demonstrated unusual patterns of tumour expansion in cystectomy specimens after previous transurethral resections. When transurethral resection had been per- formed, bladder tissues showed clusters of malignant cells in between muscle fibres and perivesical fat. They concluded that tumour cells were brought into the surrounding tissue when deep resections were performed. Cystectomy specimens from patients who had not undergone a previous transurethral resection did not show cancer cells in adjacent tissues. Therefore, higher progression rates may be expected in differentiated resections with deep resection of the tumour ground. The progression rate in this study, however, did not show statistically significant differences between both groups. There was no evidence that differentiated resections led to aggressive growth by releasing tumour cells into deeper muscle layers. Indeed, the resection technique with a separate elimination of the tumour base and surroundings showed a much higher rate of tumour-free second resections, indicating a higher rate of tumour elimination at the first treatment.

Experimental data suggest possible influences of transurethral resections on cell adhesion and migration. The tumour cell implantation is enhanced by intravesical trauma resulting from enlarged areas of uncovered extracellular matrix $[3,12]$. This implantation theory is supported by the fact that most metachronous and synchronous tumours are of the same clonal origin $[2,13]$. Whether cells had seeded before surgery or were disseminated during the resection cannot be determined.

The challenge is to verify the implantation theory and to transfer in vitro data to clinical applications. The current study can be a step in estimating the advantage or disadvantage of differentiated resection of bladder tu- 
mours. Although there are many aspects influencing recurrence and progression, it is clinically relevant to demonstrate that the differentiated resection method is not associated with perceived disadvantages, such as increased tumour recurrence or progression.

Attempts to lower recurrence rates by using laser resection seemed promising, but subsequent studies could not confirm better outcomes. Beisland and Seland [14] achieved a significant reduction in recurrence rates by performing laser resection, implying that less urothelial trauma and fewer free-floating tumour cells result in a lower recurrence rate. Sakkas et al. [15] demonstrated a decrease in the local recurrence rate only, but the overall recurrence was $45 \%$.

This study did not show any significant differences between the two techniques employed. The data showed equivalent results with respect to recurrence and progression rates in both groups. Further prospective randomized studies are needed to provide comparative data using various resection techniques, including laser resections, and the benefits of instillation therapies. Since early instillation therapy significantly reduces recurrences within the first 24 months, perioperative cell seeding can be better addressed [16]. Mitomycin or equivalent chemotherapeutic agents are proposed for lowering recurrence rates by destroying floating tumour cells rather than influencing already seeded but invisible tumours, as chemoresection does.

\section{Conclusions}

Overall, the findings in this study show that both differentiated and non-differentiated operating techniques provide equivalent outcomes with respect to recurrence and progression rates. Extensive tumour resection with the differentiated technique does not influence recurrence and progression rates, but it is an effective tool for reducing the risk for tumour persistence and facilitates more precise staging. The combination of differentiated resection and early instillation therapy for superficial bladder cancer is recommended.

\section{References}

-1 Pawinski A, Sylvester R, Kurth KH, Bouffioux C, van der Meijden A, Parmar MK, Bijnens L: A combined analysis of European Organization for Research and Treatment of Cancer and Medical Research Council randomized clinical trials for the prophylactic treatment of stage TaT1 bladder cancer. J Urol 1996;156:19341940.

$>2$ Hartmann A, Rosner U, Schlake G, Dietmaier W, Zaak D, Hofstaedter F, Knuechel R: Clonality and genetic divergence in multifocal lowgrade superficial urothelial carcinoma as determined by chromosome 9 and p53 deletion analysis. Lab Invest 2000;80:709-718.

$\checkmark 3$ Pode D, Alon Y, Horowitz AT, Vlodavsky I, Biran S: The mechanism of human bladder tumour implantation in an in vitro model. J Urol 1986;136:482-485.

$\checkmark 4$ Bressel M, Kemper K, Stadtler F: Requirements and technic of transurethral electroresection of bladder carcinoma. Urologe 1969;8: 73-80.

$\checkmark 5$ Grimm MO, Steinhoff C, Simon X, Spiegelhalder P, Ackermann R, Vögeli TA: Effect of routine repeat transurethral resection for superficial bladder cancer: a long-term observational study. J Urol 2003;170:433-437.

\footnotetext{
6 Flamm J, Steiner R: Stellenwert der differenzierten transurethralen Resektion beim primären oberflächlichen Harnblasenkarzinom (English abstract). Urologe A 1991;30:111113.

7 Oosterlinck W: Guidelines on diagnosis and treatment of superficial bladder cancer. Minerva Urol Nefrol 2004;56:65-72.

-8 Oosterlinck W, Löbel B, Jakse G, Malmström PU, Stöckle M, Sternberg C; European Association of Urology (EAU) Working Group on Oncological Urology: Guidelines on bladder cancer. Eur Urol 2002;41:105-112.

$>9$ Mack D, Rammal E, Jakse G: Iatrogene Tumorzellimplantation beim Blasenkarzinom (English abstract). Urologe A 1988;27:99_ 104.

10 Kiemeney LA, Witjes JA, Heijbroek RP, Koper NP, Verbeek AL, Debruyne FM: Should random urothelial biopsies be taken from patients with primary superficial bladder cancer? A decision analysis. Br J Urol 1994;73:164171.

11 El-Abbady AA, Shoukry MS, Hanno AG, Younis LK, Abdel-Rahman: Repeated transurethral resection of recurrent superficial bladder tumors - does it affect the spread and stage of the tumor? Scand J Urol Nephrol 2002;36:6064.

12 Soloway MS, Masters S: Urothelial susceptibility to tumour cell implantation (influence of cauterization). Cancer 1980;46:1158-1163.

13 Hafner C, Knuechel R, Stoehr R, Hartmann A: Clonality of multifocal urothelial carcinomas: 10 years of molecular genetic studies. Int J Cancer 2002; 101:1-6.

14 Beisland HO, Seland P: A prospective randomized study on neodymium-YAG laser irradiation versus TUR in the treatment of urinary bladder cancer. Scand J Urol Nephrol 1986;20: 209-212.

15 Sakkas G, Karagiannis A, Karayannis D, Dimopoulos K: Laser treatment in urology: our experience with neodymium:YAG and carbon dioxide lasers. Int Urol Nephrol 1995;27:405412.

16 Langbein S, Haecker A, Badawi JK, Michel MS, Alken P: Early instillation in superficial bladder carcinoma: current status. Urologe A 2004; 43:1531-1536.
} 